pulmonary atresia, (2) associated with systemic obstruction-aortic arch interruption, and (3) with unrestricted systemic and pulmonary flows. PFAA might be asymptomatic when it forms a subclavian artery arising from the ascending aorta (type A3) ${ }^{3}$ or a double-lumen (subway) type of aortic arch in the absence of aortic interruption or coarctation (type A1). ${ }^{1}$ No intervention is needed in such patients. At the other end of the spectrum, it might be an isolated anomaly connecting the ascending aorta to the PA, leading to increased pulmonary blood flow and heart failure (type B3). ${ }^{4}$

PFAA can have a beneficial hemodynamic role in both systemic-systemic and systemic-pulmonary configurations. It serves as a conduit for systemic blood flow when associated with aortic atresia, aortic arch interruption, or aortic coarctation ${ }^{1}$ and pulmonary blood flow when associated with pulmonary atresia. ${ }^{5}$ The varied clinical presentation of this entity leads to misdiagnosis and under- estimation of the true incidence of PFAA. Gerlis and colleagues $^{1}$ report an incidence of 1 in 330 autopsy cases in an analysis of 2000 pathologic specimens. Familiarity with the different clinical presentations will aid in avoiding misdiagnosis of this entity.

\section{References}

1. Gerlis LM, Ho SY, Anderson RH, Da Costa P. Persistent 5th aortic arch—a great pretender: three new covert cases. Int J Cardiol. 1989;23:239-47.

2. Oppido G, Davies B. Subclavian artery from ascending aorta or as the first branch of the aortic arch: another variant of persistent fifth aortic arch. J Thorac Cardiovasc Surg. 2006;132:730-1.

3. Moes CA, Benson LN, Burrows PE, Freedom RM, Williams W, Duckworth JW. The subclavian artery as the first branch of the aortic arch. Pediatr Cardiol. 1991;12:39-43.

4. Hwang M-S, Chang Y-S, Chu J-J, Su W-J. Isolated persistent fifth aortic arch with systemic-to-pulmonary arterial connection. J Thorac Cardiovasc Surg. 2003;126: 1643-4.

5. Khan S, Nihill MR. Clinical presentation of persistent 5th aortic arch. Tex Heart Inst J. 2006;33:361-4.

\title{
Treatment of deep sternal wound infections after coronary artery bypass grafting by means of injection of platelet gel: An evolving technology
}

\author{
Erez Kachel, MD, ${ }^{\mathrm{a}}$ Jeannie Callum, MD,${ }^{\mathrm{b}}$ Fuad Moussa, MD, ${ }^{\mathrm{a}}$ Jenette Goldstein, MLT, ${ }^{\mathrm{b}}$ and \\ Stephen Fremes, MD, ${ }^{\mathrm{a}}$ Toronto, Ontario, Canada
}

Deep sternal wound infections (DSWIs) continue to be one of the most devastating and potentially life-threatening complications after cardiac surgery. Although most patients are treated surgically, there is high rate of recurrent infection or flap-related complications and mortality. ${ }^{1}$ Lately, nonsurgical methods, such as vacuum-assisted closure (VAC), injection of activated macrophages, or both, have shown promising results. ${ }^{2,3}$

Platelet gel (PG) contains concentrated levels of plateletsecreted growth factors (platelet-derived growth factor and vascular endothelial growth factor) and other substances

\footnotetext{
From the Division of Cardiac and Vascular Surgery ${ }^{\mathrm{a}}$ and Transfusion Medicine and Tissue Bank, ${ }^{\mathrm{b}}$ Sunnybrook Health Sciences Center, Toronto, Ontario, Canada. Disclosures: None.

Received for publication Feb 5, 2009; revisions received April 21, 2009; accepted for publication April 25, 2009; available ahead of print June 11, 2009.

Address for reprints: Erez Kachel, MD, C/o Sunnybrook Health Sciences Centre, 2075 Bayview Ave, Room H410, Toronto, Ontario, Canada M2N 3M5 (E-mail: erezk@ bezeqint.net).

J Thorac Cardiovasc Surg 2010;139:e118-20

$0022-5223 / \$ 36.00$

Copyright (c) 2010 by The American Association for Thoracic Surgery doi:10.1016/j.jtcvs.2009.04.025
}

that have the potential to accelerate wound healing, epithelialization, and granulation tissue formation. ${ }^{4}$ Autologous PG has been used in the treatment of various wound infections, although not sternal wounds. ${ }^{2}$ We present a case using allogeneic PG to facilitate wound closure.

\section{CLINICAL SUMMARY}

A 74-year-old diabetic, hypertensive, and morbidly obese (body mass index, 42) woman was readmitted with sepsis 5 weeks after triple coronary artery bypass grafting with a single pedicled thoracic artery. Before admission, the patient was treated for 10 days with oral ciprofloxacin because of sternal incision erythema. On admission, the sternum was now unstable with purulent discharge, and the patient was critically ill, with respiratory failure requiring intubation and mechanical ventilation; was hemodynamically unstable, requiring vasopressor support; and had renal insufficiency. Cultures were taken, and intravenous vancomycin was started. She was taken to the operating room on an emergency basis for surgical debridement at which time the sternal wires were removed, all grossly necrotic tissue was 


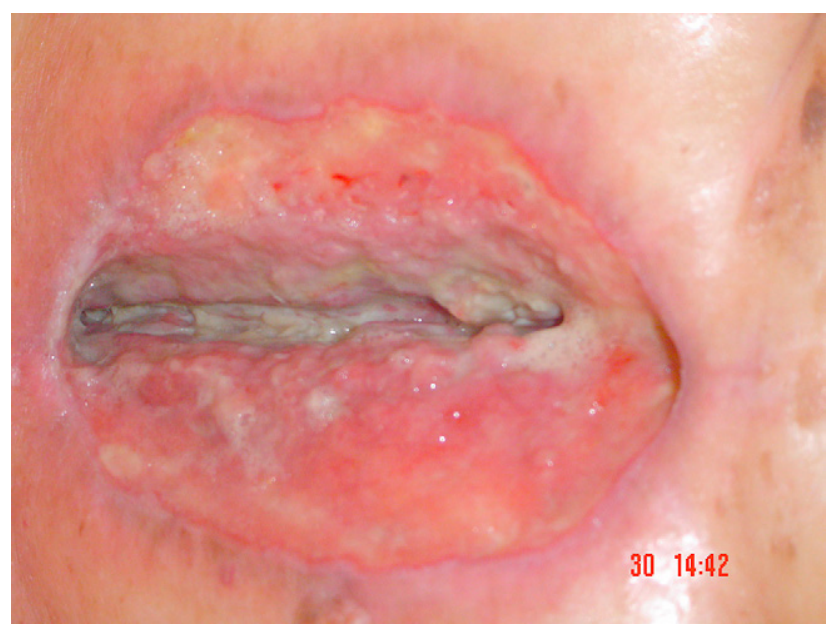

FIGURE 1. Deep sternal wound infection before treatment.

excised, and the wound was left open. The diagnosis of DSWI was established based on clinical judgment, intraoperative findings, and tissue, bone, and blood cultures, results of which were positive for methicillin-resistant Staphylococcus aureus sensitive to vancomycin (Figure 1).

The patient was treated with VAC for the next 4 weeks, with minimal evidence of wound healing. Because she was at high risk for sternal reconstruction failure because of morbid obesity with a high volume of purulent discharge, we treated her by injecting allogeneic PG into the sternal wound, followed by another course of VAC.

In our institution bedside sternal debridement is performed before $\mathrm{PG}$ injection. We inject the $\mathrm{PG}$ with a $10-\mathrm{mL}$ syringe, $0.1 \mathrm{~mL} / 1 \mathrm{~cm}^{2}$ into the soft tissues and periosteum, to a depth of 0.5 to $1 \mathrm{~cm}$ targeting viable tissue (ie, not into fibrin or necrotic tissue). Thereafter, lactated Ringer's soaked sterile gauze pads are applied twice daily for the next 2 days until the VAC system is reapplied.

The allogeneic PG is prepared as follows: a pool of groupspecific, buffy-coat-prepared, leukoreduced, bacterially depleted platelets ( 4 donations) is centrifuged at $22^{\circ} \mathrm{C}$ and $2400 \mathrm{rpm}$ for 10 minutes. The plasma is extracted, leaving approximately $50 \mathrm{~mL}$ of residual volume. The concentrated platelets are resuspended gently in the remaining plasma by means of gentle manipulation of the product. The product is then left to rest for approximately 15 minutes and then placed on the blood bank platelet agitator for another 30 minutes before issue.

Two weeks after the first PG injection, the whole bone was covered with strong, bright granulation tissue (Figure 2). Two more doses were injected in 2-week intervals, and final closure was achieved 8 weeks after the first injection (Figure 3).

\section{DISCUSSION}

The use of allogeneic PG for treatment of postoperative DSWIs represents an innovative and conservative biologic

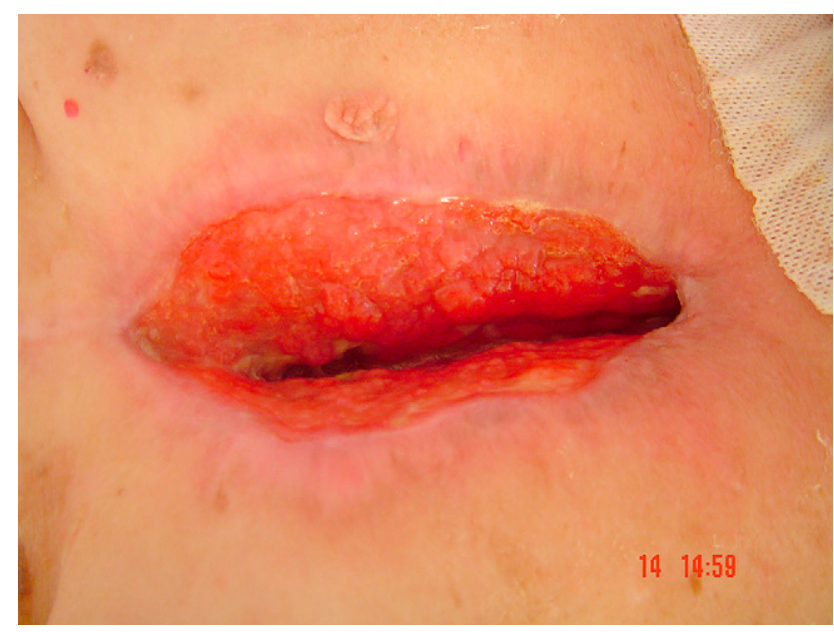

FIGURE 2. Two week after the first platelet gel injection.

approach for this disastrous complication. The only 2 published articles that used PG in cardiac surgeries applied autologous PG on the wound surface area at the end of the operation as prophylaxis against wound infection rather than as therapy for established DSWI, as in our case. ${ }^{5}$

The combination of a very high-risk patient for a second operation, the evidence that PG accelerates wound healing in other disciplines, and the knowledge that PG contains and secretes many growth factors involved in wound healing encouraged us to treat the patient with this novel approach. Although there is no scientific proof that PG was responsible for the accelerated wound healing, wound healing had not progressed for at least 4 weeks after conventional therapy, including operative debridement, local wound care with a VAC dressing, and appropriate antibiotics. After injection of the PG and without introduction of any other therapy, the wound was granulated in 2 weeks without any further intervention.

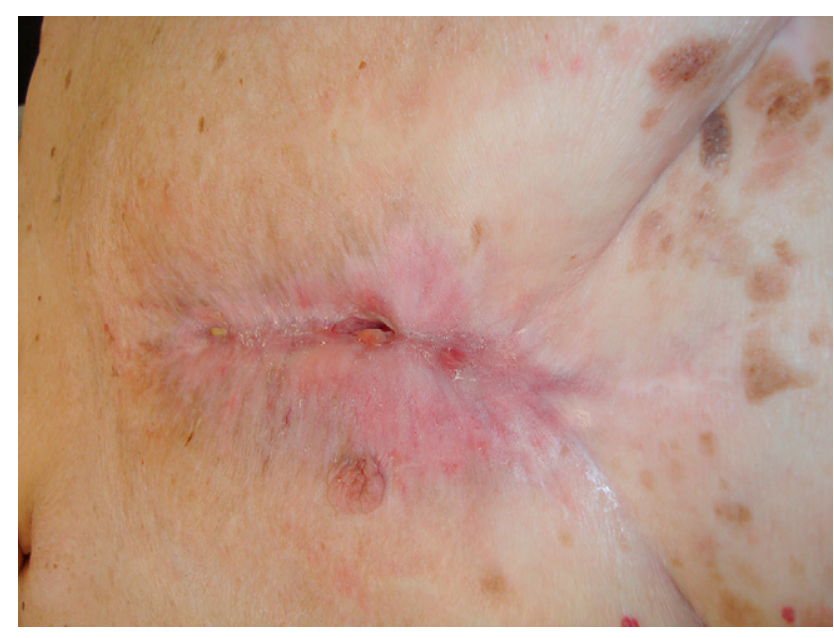

FIGURE 3. Eight weeks after the first platelet gel injection. 
Allogeneic PG, as opposed to autologous PG, is preferred because it can be obtained from young and healthy donors, providing a high dose of functioning platelets with minimal risk of bacterial contamination.

This is the first published report, to our knowledge, of treating DSWI by means of injection of allogenic PG. Considering the disappointing results seen with the surgical treatment of DSWI, especially for high-risk patients, nonsurgical therapy consisting of a combination of biologic (PG) and mechanical (VAC) methods might be advantageous as a simple, inexpensive, and safer therapy.

\section{References}

1. Yuen JC, Zhou AT, Serafin D, Georgiade GS. Long-term sequelae following median sternotomy wound infection and flap reconstruction. Ann Plast Surg. 1995;35:585-9.

2. Orenstein A, Kachel E, Zuloff-Shani A, Paz Y, Sarig O, Haik J, et al. Treatment of deep sternal wound infection post open heart surgery by application of activated macrophages suspension. Wound Repair Regen. 2005;13:237-42.

3. Sjögren J, Mokhtari A, Gustafsson R, Malmsjö M, Nilsson J, Ingemansson R. Vacuum-assisted closure therapy for deep sternal wound infections: the impact of learning curve on survival and predictors for late mortality. Int Wound J. 2008;5:216-23.

4. Hom DB, Linzie BM, Huang TC. The healing effects of autologous platelet gel on acute human skin wounds. Arch Facial Plast Surg. 2007;9:174-83.

5. Trowbridge CC, Stammers AH, Woods E, Yen BR, Klayman M, Gilbert C. Use of platelet gel and its effects on infection in cardiac surgery. J Extra Corpor Technol. $2005 ; 37: 381-6$

\title{
Right ventricular reverse remodeling is possible despite twenty-one years of absent tricuspid valve and severe right ventricular failure
}

\author{
Ramohan Marla, MD, Judy Fox, RNP, Raymond Q. Migrino, MD, Lee Biblo, MD, and R. Eric Lilly, MD, \\ Milwaukee, Wis
}

Recovery of impaired right ventricular (RV) function after tricuspid valve (TV) replacement for long-standing chronic tricuspid regurgitation is not predictable. Poor preoperative $\mathrm{RV}$ function and enlarged RV dimensions are not always reversible after TV replacement. We report a case of complete return to normal of RV dimensions and function after TV replacement for severe tricuspid regurgitation of 21 years' duration.

\section{CLINICAL SUMMARY}

A 48-year-old woman with history of TV excision at another institution 21 years previously for staphylococcal endocarditis was admitted with class IV heart failure. During the ensuing 5 years, she had progressively worsening functional status and finally was seen with overt right heart failure in atrial flutter with ascites and pleural effusions. A transthoracic echocardiogram revealed a small left ventricle with leftward displacement of the interventricular septum, severely dilated RV with diminished RV systolic function, and absent TV (Figure 1, $A-C$ ). Right heart catheterization revealed Fick-derived cardiac index of $1.57 \mathrm{~L} /$

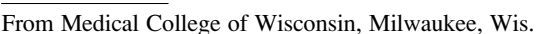

Disclosures: None.

Received for publication April 23, 2009; accepted for publication May 17, 2009; available ahead of print July 30, 2009

Address for reprints: R. Eric Lilly, MD, Medical College of Wisconsin, Cardiothoracic Surgery, Froedtert East, Suite 5700, 9200 W Wisconsin Ave, Milwaukee, WI 53226 (E-mail: relilly@mcw.edu).

J Thorac Cardiovasc Surg 2010;139:e120-2

$0022-5223 / \$ 36.00$

Copyright (c) 2010 by The American Association for Thoracic Surgery doi:10.1016/j.jtcvs.2009.05.018 $\left(\mathrm{min} / \mathrm{m}^{2}\right)$, pulmonary vascular resistance of 3.86 Wood units, and pulmonary capillary wedge pressure of $19 \mathrm{~mm}$ $\mathrm{Hg}$. No coronary artery disease was noted on left heart catheterization.

A 33-mm St Jude Biocor porcine valve (St Jude Medical, Inc, St Paul, Minn) was sutured into the tricuspid position by way of a resternotomy. Midrange inotropic support without nitric oxide was required for successful weaning from cardiopulmonary bypass. Cardiac index gradually improved, and the patient was discharged home on postoperative day 14 in normal sinus rhythm. A transthoracic echocardiogram obtained 6 months after surgery demonstrated RV reverse remodeling with improved left ventricular geometry (Figure $1, D-F$ ) and normal RV dimensions, as defined by the American Society of Echocardiography ${ }^{1}$ (Table 1). At 6 months, the patient had no signs of heart failure and nearly normal exercise tolerance.

TABLE 1. Right ventricular chamber dimensions preoperatively and at 6 postoperative months of follow-up

\begin{tabular}{lccc}
\hline \multicolumn{1}{c}{ Measurement } & $\begin{array}{c}\text { Reference range } \\
(\mathbf{c m})\end{array}$ & $\begin{array}{c}\text { Preoperative } \\
(\mathbf{c m})\end{array}$ & $\begin{array}{c}\text { Follow-up } \\
(\mathbf{c m})\end{array}$ \\
\hline $\begin{array}{l}\text { Right ventricular } \\
\text { basal diameter }\end{array}$ & $2-2.8$ & 5 & 2.8 \\
$\begin{array}{l}\text { Mid right } \\
\quad \text { ventricular diameter }\end{array}$ & $2.7-3.3$ & 3.5 & 3.2 \\
$\begin{array}{l}\text { Base to apex length } \\
\text { Above aortic valve }\end{array}$ & $7.1-7.9$ & 7.5 & 7.2 \\
$\begin{array}{l}\text { Above pulmonic valve } \\
\text { Mench }\end{array}$ & $1.7-2.3$ & 5.6 & 4.4 \\
\hline
\end{tabular}

Measurements and reference ranges were obtained according to standard American Society of Echocardiography recommendation. ${ }^{1}$ 